\title{
Konsep Integrasi Ilmu Agama Dan Ilmu Umum
}

\author{
Ali Akbar ${ }^{1}$, Agus Basri², Agus Wandi ${ }^{3}$, Herman Jamaluddin ${ }^{4}$ \\ ${ }^{1}$ Sekolah Tinggi Agama Islam (STAI) Darul Dakwah Wal-Irsyad (DDI) Kota Makassar, Indonesia \\ Email: ali.aakbar05@gmail.com \\ ${ }^{2}$ Sekolah Tinggi Agama Islam (STAI) Darul Dakwah Wal-Irsyad (DDI) Kota Makassar, Indonesia \\ E-mail: agusbasritakko@gmail.com \\ ${ }^{3}$ Sekolah Tinggi Agama Islam (STAI) Darul Dakwah Wal-Irsyad (DDI) Kota Makassar, Indonesia \\ Email: aguswandibinmursi1@gmail.com \\ ${ }^{4}$ Sekolah Tinggi Agama Islam (STAI) Darul Dakwah Wal-Irsyad (DDI) Kota Makassar, Indonesia \\ E-mail: hermanjamal1295@gmail.com
}

\section{Abstrak:}

Sudah saatnya kita harus menghilangkan dikomotomisasi antara sains dan agama, kita merindukan sebuah harmoni yang parexellence antara sains dan ruh spritualisasi agama. Sudah saatnya ,sains dan agama harus menghadirkan kesadaran yang muncul lewat pandangan-pandangan yang lebih harmanis, holistik,dan komprehenshif.

\section{Kata Kunci: Integrasi, Ilmu Agama, Ilmu Umum}

\section{PENDAHULUAN}

Pendidikan merupakan salah satu medium terbaik untuk tujuan tersebut ,karena kunci kearah masa depan yang lebih baik adalah pendidikan, dimana tujuan utama pendidikan adalah untuk memampukan budaya pengetahuan integral berakar kuat di masyarakat muslim kontemporer, sehingga kemajuan di bidang sains dan teknologi menjadi lebih muda untuk mencapai peradaban islam yang maju ${ }^{1}$.

Manusia di perintahkan untuk mencari dan mengembangkan ilmu pengetahuan baik yang bersumber pada wahyu. maupun bersumber dari alam kosmik mengetahui bahwa Tuhan seluruh alam. Untuk melihat kondisi suatu bangsa yang berkualitas adalah ketika bangsa yang maju pendidikannya, dimana pendidikan adalah penentu sebuah bangsa menjadi berkembang dan berkualitas pada dimensi ilmu pengetahuan.

\footnotetext{
${ }^{1}$ Lis arifuddin, integrasi sains dan agama serta implikasinya terhadap pendidikan islam, edukasi islamika, volume 1 ,nomor $1,(2016)$ hl. 16-17
} 


\section{PEMBAHASAN}

\section{A. Kedudukan Ilmu Pengetahuan Dalam Islam}

Ilmu dalam pandangan Al-Qur'an tidak bertentangan ,Bahkan dapat kian meneguhkan iman. Ia berjalan dengan iman secara beriringan .Allah swt.Berfirman :Allah akan meninggikan orang-orang yang beriman diantaramu dan orang yang di beri ilmu pengetahuan beberapa derajat."( QS. Al-Mujadilah/58:11).Tampak jelas bahwa manusia dengan akal dan pikirannya ,mengetahui bahwa kebenaran dan ilmu pengetahuan adalah milik tuhan semata. ${ }^{2}$ Dengan mengetahui itu seorang muslim kemudian beriman dan dengan keimanannya itulah hatinya akan tunduk kepada Allah SWT. Dengan demikian, implikasi dari makna fithrah adalah suatu kekuatan atau kemampuan yang menetap pada diri manusia sejak awal kelahirannya

Hal inimenunjukkan bahwa makrifat mendahui rasa, dan rasa mendahui gerak,baik gerak hati maupun gerak fisik. ia bahwa manusia dan akal dan pikirannya. Konstatasi diatas kian mempertegas bahwa antar ilmu dan iman, atau antara ilmu dan Agama, tidaklah bertentangan, tetapi sebaliknya justru saling meneguhkan. Sebab,kitab suci dan Sunnah Nabi mengajak kepada ilmu dan memandangnya sebagai ibadah, baik Ilmu- ilmu agama maupun non-keagamaan atau yang biasa disebut sebagai ilmu sekuler duniawi. Salah satu contoh dalam kehidupan sehari dab bahkan kebutuhan dia terhadap ilmu dalam mendidik anak melebihi kebutuhannya terhadap ilmu dalam menjalankan pekerjaannya

Atau dengan ungkapan lain, Pradikma integrasi keilmuan terbuka atau di alogis, yakni cara pandang terhadap ilmu yang terbuaka dan menghormati keberadaan jenisjenis ilmu yang ada secara proposional dengan tidak meninggalkan sifat kritis.Terbuka

\footnotetext{
${ }^{2}$ Dr.Nurman said Dkk, Islam untuk disiplin ilmu sosial,Humaniora, dan saintek. ( cet pertma, Makassar, alauddin press, 2009)., hal.97
} 
artinya suatu ilmu atau sekumpulan ilmu dapat bersumber dari ilmu umum yang bertemu saling mengisi secara konstruksi. ${ }^{3}$

\section{B. Perkembangan Ilmu Pengetahuan}

Azyumardi Azra, mengemukakan ada tiga tipologi respon cendekiawan muslim berkaitan dengan hubungan antara keilmuan agama dengan keilmuan umum. Pertama: Restorasionis, yang mengatakan bahwa ilmu yang bermanfaat dan dibutuhkan adalah

praktek agama (ibadah). ${ }^{4}$ Cendekiawan yang berpendapat seperti ini adalah Ibrahim Musa (w. 1398 M) dari Andalusia. Ibnu Taymiah, mengatakan bahwa ilmu itu hanya pengetahuan yang berasal dari nabi saja. Begitu juga Abu Al-A'la Maududi, pemimpin jamaat al-Islam Pakistan, mengatakan ilmu-ilmu dari barat, geografi, fisika, kímia, biologi, zoologi, geologi dan ilmu ekonomi adalah sumber kesesatan karena tanpa rujukan kepada Allah swt. dan Nabi Muhammad saw. Kedua: Rekonstruksionis interprestasi agama untuk memperbaiki hubungan peradaban modern dengan Islam.

Mereka mengatakan bahwa Islam pada masa Nabi Muhammad dan sahabat sangat revolutif, progresif, dan rasionalis.Sayyid Ahmad Khan (w. 1898 M) mengatakan firman Tuhan dan kebenaran ilmiah adalah sama-sama benar. Jamal alDin al-Afgani menyatakan bahwa Islam memiliki semangat ilmiah.

Ketiga: Reintegrasi, merupakan rekonstruksi ilmu-ilmu yang berasal dari alayah al-qur'aniyah dan yang berasal dari al-ayah al-kawniyah berarti kembali kepada kesatuan transsendental semua ilmu pengetahuan." Bekas bekas tangan para insinyur dan arsitek muslim ini masi dapat dilihat samapai saat ini khususnya masjid Kordova dan masjid sultan Muhammad di Istanbul dan lain-lain. Rekayasa para ilmuan dan

\footnotetext{
${ }^{3}$ Miftahuddin, integrasi pengetetahuan umum dan keislaman di Indonesia,studi integrasi keilmuan di UIN di Indonesia, Attarbiya, Vol.1 No.1 (2016) hal.7

${ }^{4}$ Ansharullah, kajian tinggkat pemahaman knsep integrasi ilmu dan islam antara dosen bidang ilmu umum dengan dosen bidang ilmu agama di fakultas ilmu tarbiya dan keguruan UIN Jakrta, POTENSI , jurnal kependidikan islam, vol 2.,no.1 (2016).hal 4
} 
teknologi muslim dahulu itu tidak menimbulkan.efek samping yang negative, karna titik tolak mereka dalam mengamalkan ilmu pengetahuan dan teknologi ialah manifestasi rasa syukur mereka kepada Allah Swt. ${ }^{5}$

Dapatlah kiranya dipahami, mengapa Al-Quran didalam sejarah telah terbukti merupakan inspirasi, Motivator, bahkan pedoman bagi setiap mukmin didalam mempelajari ilmu dan teknologi. Para ulama Muslim telah muncul ketengah-tengah pentas dunia sebagai pelopor dalam memajukan ilmu dan teknologi, karena jalan pikiran mereka berorentasi kepada kitabullahini, dan motivator mereka terutama ialah kecintaan mereka Allah dan Rasulnya, yang telah mempusakakan kitab yang perna beliau katakana sebagai mukjizat beliau dari allah swt.ahan rahmat, nikmat serta kesehatan sehingga penulis bisa menyelesaikan sebuah Makalah yang berjudul “Urgensi memahami Teori teori belajar dalam Pembelajaran". Shalawat serta salam semoga dilimpahkan kepada sang revolusioner akbar Nabi Muhammad saw. Yang telah menunjukkan kita semua menuju ke jalan yang bahagia di dunia dan akhirat.

Pada musim gugur 1975 bertempat di Gustavus Adolphus College, Minnesota, terjadi sebuah peristiwa menarik, pada waktu itu sebanyak 27 orang pemenang Hadiah Nobel dari berbagai disiplin ilmu dari orang ahli agama bekonferensi untuk membicarakan masa depan sains di depan 4000 orang hadirin yang terdiri dari agamawan, ilmuwan dan mahasiswa (Robinson, h. Xiii). Kejadian ini menarik karena menggambarkan "keakraban" antara pihak agamawan dan ilmuwan di abad ke 20 ini ${ }^{6}$.

Walaupun perpecahan antara ilmuwan dan agamawan tak tercatat dalam sejarah perkembangan (IPTEK) di Indonesia, tapi himbauan agar ilmuwan dan agamawan saling mendukung terdengar juga gemanya di sini. misalnya ajakan Prof.

\footnotetext{
${ }^{5}$ Dr.Nurman said Dkk, Islam untuk disiplin ilmu sosial,Humaniora, dan saintek. Hal.100

${ }^{6}$ Moeflich Hasbulla, gagasan dan perdebatan islamisasi ilmu pengetahuan, ( Pt pustaka cidesindo, jakrta, 2000) hal.86
} 
Dr. Soedjatmoko, mantan rektor Uni- versitas PBB, yang menyerukan agar ulama ikut memilih teknologi dan memecahkan masalah duniawi (Suara Pembaharuan, 23 Nov, 1989 dan Ummul Qur -an V. 2, 1989). Simaklah pula pendapat Prof. Baiquni yang menyatakan bahwa ilmu pengetahuan dan Teknologi (IPTEK) terus manerus memerlukan bantuan agama (Pelita, 20 Nov. 1989).Perhatikankah pula tulisan Y. B. Mangunwijaya yang mengajak kita untuk menarik hikmah dari Galileo Galilei (Kompas, 7 Nov 1989 dan 20 Nov. 1989).Bahkan kehadiran Ulumul Qur_an ini sendiri memperhatikan keinginan untuk memesrakan hubungan antara ilmuwan dan agamawan.

Pikiran bahwa agama dan ilmu saling melengkapi, mewarnai bahkan merupakan pijakan dasar tulisan ini.Dengan demikian keterangan diberikan dan analisa diajukan berdasarkan asumsi bahwa, agama di satu pihak dapat menjadi landasan etika dalam upaya pengembangan dan paserapan ilmu dan teknologi. Dan IPTEK di pihak lain dapat membantu mengamalkan nilai-nilai agama.

\section{Konsep Aksiologis}

Jujun S. Suriasumantri menjelaskan tujuan pengenbangan IPTEK menurut versi ilmuwan Menurutnya ilmu itu mempelajari gejala alam apa adanya dengan tujuan manusia dapat mengungkapkan rahasia alam dan menciptakan peralatan untuk mengontrol gejala-geiala tersebut sesuai dengan hukum alam. Selain itu juga dengan perkembangan IPTEK saat sekarang ini misalnya pendidikan karakter yang didapatkan dari keluarga, pendidikan keahlian, pendidikan tata krama, dan lain-lain. Semua hal tersebut dapat kita control dengan penggunaan teknologi.

Teknologi sendiri adalah penerapan pengetahuan ilmiah dalam bentuki manusia memecahkan masalah kehidupan yang bersifat praktis.Peralatan ini bisa berupa perangkat lunak berupa metode dan teknik atau fisik (Suara Pembaruan, 18 Sep- tember 
1989).Al- Qur'an sesungguhnya memberikan etika dan tujuan pengembangan IPTEK yang secara sistematis dapat dibagi dua. Pertama, untuk membantu manusia mendekatkan diri kepada Allah Swt. Kedua, untuk membantu manusia menjalankan tugas kekhalifahannya di bumi . ${ }^{7}$

\section{Konsep Iptek Meningkatkan Ketaqwaan}

Apa betul IPTEK dapat membantu manusia untuk lebih menyadari kebesaranNya? Untuk pertanyaan ini, Allah Swt telah menyediakan jawaban di dalam al-Qur'an. Simaklah apa yang difirmankannya dalam surah Al-Jatsiyah (berlutut):

Susunya ngguh, di langit dan di bumi, ada tanda-tanda (kekuasaan Tuhan) bagi orang yang beriman (Q.S. 45:3)

Pada dirimu yang la ciptakan, dan pada binatang yang la tebarkan, Nampak (pula) tanda-tanda (kekuasaan bagi orang yang punya keyakinan (Q.S. 45: 4).

Pun pada malam yang silih berganti dengan siang, dan rezeki yang Allah turunkan dari langit, Kemudian laIslamisasi Imu Pongetahuari hidupkan bumi dengannya sesudah mati, Dan pada perkisaran angin, Nampak tanda-tanda (kekuasaan Tuhani Bagi orang yang menggunakan akal pikiran (QS. 45 5)

Pada terjemahan ayat-ayat yang dikutipkan di atas dinyatakan bahwa sesungguhnya kemanapun kita palingkan wajah kita,${ }^{8}$ tanda tanda kebesaran-Nya akan kita temukan tapi dengan kondisi dasar: Kita harus beriman, yakin, dan menggunakan akal pikiran. Jika dengan segala kerendahan hati kita coba simak makna sebagian dari ayat 3 surat Al- Jatsiyah di atas, maka kita dengan serta merta dapat mengerti betapa akal pikiran dapat menyadarkan kita akan kebesaran Allah.

\footnotetext{
${ }^{7}$ Moeflich Hasbulla, gagasan dan perdebatan islamisasi ilmu pengetahuan,) hal.87

${ }^{8}$ Moeflich Hasbulla, gagasan dan perdebatan islamisasi ilmu pengetahuan hal. 88
} 
Serta betapa IPTEK dapat membuat kita bersimpuh dan berlutut menyadari kekecilan kita sebagai hamba Allah.Surah tersebut menyatakan bahwa di langit dan di bumi terdapat tanda tanda kekuasaan Tuhan.Mari kita coba menganalisanya lebih jauh. Umumnya, orang beriman yang membaca ayat tersebut akan berpikir atau berimajinasi tentang langit biru serta matahari yang dilihatnya di siang hari, serta bulan yang bercahaya dan bintang yang gemerlapan yang disaksikannya di malam hari. Tapi pikiran dan imaji seorang yang memiliki ilmu yang cukup dalam bidang kosmologi dan astronomi akan menerobos dan menembus jauh ke kedalaman samudra angkasa luar dengan segala yang ada di dalamnya. Orang yang berilmu tadi akan memikirkan betapa maha luasnya alam ciptaan Tuhan dan betapa banyaknya isi yang ada di dalamnya. Dan kesemuanya ini akan membuatnya berlutut dan bersujud menyadari kemahabesaran Allah.

Baru saja bulan November 1989 yang lalu, ilmuwan dengan perangkat teknologinya berhasil mengintip Quasar yang jauhnya 14 milyar tahun cahaya dari bumi tempat kita bermukim (Kompas, 26 November 1989). Membaca berita ini membuat ilmuan yang beriman untuk mengucapkan 'Allahu Akbar' dengan sanubari bergetar. ${ }^{9}$ Untuk dapat ilmu pengetahuan, seseorang harus menggunakan akalnya. Hal ini di perkuat dengan firman yang menyatakan bahwa" menumpakan kemurkaan " bagi orang yang tidak menggunakan akalnya.

Dan tidak ada seorang pun akan beriman kecuali dengan izin Allah; dan Allah menimpakan kemurkaan kepada orang- orang yang tidak menggunakan akalnya. (QS Yunus [10]: 100)

\footnotetext{
${ }^{9}$ Moeflich Hasbulla, gagasan dan perdebatan islamisasi ilmu pengetahuan hal.89
} 
Dan Al-Quran juga menegaskan bahwa menjadi pengikut yang pasif, dengan hati yang beku dan tidak kritis ${ }^{10}$, sangat tidak dianjurkan.Setiap individu Muslim dikehendaki memiliki kesadaran dan pengetahuan dalam menyikapi dan menerima sesuatu yang datang kepadanya, berupa penemuan, informasi, maupun pengetahuan. Ikut-ikutan adalah sikap mental yang tidak Qurani, umat Islam harus menjauhinya. Sedang teknologi adalah pengetahuan dan keterampilan yang merupakan penerapan ilmu pengetahuan dalam kehidupan manusia sehari-hari. Perkembangan iptek, adalah hasil dari segala langkah dan pemikiran untuk memperluas, memperdalam, dan mengembangkan iptek.

Apa saja yang akan dilakukan oleh seorang Muslim harus berdasarkan pertimbangan akal budi-hati nuraninya yang telah mendapat masulan dari apa yang dilihat dan didengar. Dengan kata lain, sikap seperti ini adalah sikap kritis dari seorang intelektual. Pendengaran, penglihatan, dan hati yang dibekalkan oleh Allah kepada setiap manusia kelak pasti akan dimintai pertanggungjawabannya. Sikap kritis yang tidak menerima begitu saja informasi apa yang datang kepadanya dan cerdas memutuskan apa yang akan dilakukannya adalah sikap yang saintifik.. Perkembangan ilmu yang begitu pesat di zaman modern atau dengan istilah revolusi industri 4.0 berharap dari aspek nilai-nilai Agama dan Agama dapat dijadikan Arah dalam menentukan perkembangan ilmu selanjutnya.

Maka tidaklah mengejutkan apabila Dr. Maurice Bucaille mengambil kesimpulan bahwa: "It comes as no surprise to learn that religion and science have always been considered to be twin sisters by Islam" Apabila beliau menyadari bahwa Islam memberi tempat tinggi kepada ilmu pengetahuan atau sains, hal ini sebenarnya hal yang lumrah dan wajar saja bagi Muslim ${ }^{11}$.

\footnotetext{
${ }^{10}$ Agus S. Djamil, Al-Quran dan lautan, ( cet.1., PT Mirzan Pustaka, Bandung,.2004) hl.50

${ }^{11}$ Agus S. Djamil, Al-Quran dan lautan, hl.51-52
} 


\section{KESIMPULAN}

Dari berbagai penjelasan di atas maka dapat di simpulakn bahwa pada dasarnya Al-Quran Membimbing Perkembangan Ilmu Pengetahuan Di dalam menyimak lautan dalam Al Quran ini, kita akan semakin yakin bahwa Al-Quran adalah petunjuk jalan kebenaran, tidak ada keraguan di dalamnya, kemuliaannya dan kesuciannya itu membawa berita gembira bagi orang membaaca dan meyakininya

\section{DAFTAR PUSTAKA}

Lis arifuddin, integrasi sains dan agama serta implikasinya terhadap pendidikan islam, edukasi islamika, volume 1,nomor 1, (2016) hl. 16-17

Arsyam, M., \& Umar, K. (2020). MANUSIA SEBAGAI PENDIDIK PERPEKTIF ISLAM DAN BARAT.

Dr.Nurman said Dkk, Islam untuk disiplin ilmu sosial,Humaniora, dan saintek. ( cet pertma, Makassar, alauddin press, 2009)., hal.97

Sapada, A. O., \& Arsyam, M. (2020). Ilmu Pengetahuan dan Teknologi Menurut Pandangan Islam.

Miftahuddin, integrasi pengetetahuan umum dan keislaman di Indonesia,studi integrasi keilmuan di UIN di Indonesia, Attarbiya, Vol.1 No.1 (2016) hal.7

Arsyam, M. (2021). BAHAN AJAR ADMINISTRASI PENDIDIKAN.

Ansharullah, kajian tinggkat pemahaman knsep integrasi ilmu dan islam antara dosen bidang ilmu umum dengan dosen bidang ilmu agama di fakultas ilmu tarbiya dan keguruan UIN Jakrta,POTENSI , jurnal kependidikan islam, vol 2.,no.1 (2016).hal 4

Sapada, A. O. (2020). Mendidik Anak Menjadi Anak Sholeh.

Moeflich Hasbulla, gagasan dan perdebatan islamisasi ilmu pengetahuan, ( Pt pustaka cidesindo, jakrta, 2000)

Rifqi, N., Fajrin, M. F., \& Arsyam, M. (2021). Ibadah Sebagai Aspek Ritual Ummat Islam.

Agus S. Djamil, Al-Quran dan lautan, ( cet.1., PT Mirzan Pustaka, andung,.2004) 
